\title{
A Rupture of a Lung Metastatic Lesion of Colon Cancer, Leading to Pneumothorax Caused by Bevacizumab
}

\author{
Tomoya Iida, Takashi Yabana, Suguru Nakagaki, Takeya Adachi and Yoshihiro Kondo
}

\begin{abstract}
The patient was a 57-year-old man who was diagnosed with multiple lung metastases of sigmoid colon cancer. The patient developed progressive disease after 8 courses of bevacizumab + capecitabine and oxaliplatin therapy, therefore, bevacizumab + irinotecan, leucovorin, and 5-fluorouracil therapy was started. During the fifth course, he experienced pain on the left side of his chest. On computed tomography, bleeding from the pulmonary metastatic lesions was suspected. Two days later, a pneumothorax was detected. Although several cases of pneumothorax induced by bevacizumab have been reported, this case is the first documentation that bevacizumab caused a rupture of the lung metastatic lesion, leading to a pneumothorax.
\end{abstract}

Key words: bevacizumab, colon cancer, lung metastasis, rupture, bleeding, pneumothorax

(Intern Med 55: 3125-3129, 2016)

(DOI: 10.2169/internalmedicine.55.7155)

\section{Case Report}

The patient was a 57 -year-old man who had been treated for diabetes; he did not have a history of smoking. He visited our department because of bloody stool. Lower gastrointestinal tract endoscopy showed a tumor lesion in the entire circumference of the sigmoid colon, through which an endoscope could not be passed. A biopsy showed welldifferentiated adenocarcinoma, and computed tomography (CT) findings suggested multiple lung metastases in both lung fields (Fig. 1); therefore, colon cancer cStage IV A [according to the Unio Internationalis Contra Cancrum (UICC)] was diagnosed. Because intestinal stenosis due to the tumor was observed, sigmoidectomy was performed. The colon cancer was classified as pT3N2bM1a, pStage IV A (UICC); $K R A S$ mutations were not detected. After bevacizumab (BV) (7.5 $\mathrm{mg} / \mathrm{kg}$ on day 1$)+$ XELOX (capecitabine, oxaliplatin) therapy was started, cavitation within the pulmonary metastatic lesions was found (Fig. 2); the cavitation was considered to be caused by BV. After 8 courses of this regimen, lung metastases showed a transition to progressive disease. Thereafter, BV (7.5 mg/kg on day 1) + FOLFIRI [irinotecan (CPT-11), 1-leucovorin, 5-fluorouracil (5-FU)] therapy was started. On day 4 of course 5 , the patient experienced pain on the left side of his chest and visited our department.

The chest pain was persistent and did not increase or decrease while breathing. The patient's body-mass index (BMI) was $22.1 \mathrm{~kg} / \mathrm{m}^{2}$, body temperature was $37.0^{\circ} \mathrm{C}$, and blood oxygen saturation was $97 \%$; furthermore, on chest examination, he did not show any abnormality. The results of his blood tests were as follows: white blood cell count:

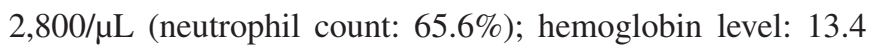
$\mathrm{g} / \mathrm{dL}$; platelet count: $151 \times 10^{3} / \mu \mathrm{L}$; lactate dehydrogenase level: $198 \mathrm{IU} / \mathrm{L}$; and C-reactive protein level: $0.06 \mathrm{mg} / \mathrm{dL}$. The blood test results for inflammatory markers were unremarkable. The test results for procalcitonin, $\beta$-D-glucan, mycoplasma antibodies, Chlamydophila psittaci antibodies, Legionella urinary antigen, Candida antigen, Aspergillus antigen, and Cryptococcus antigen were negative; therefore, infection was ruled out. The levels of surfactant protein (SP)A, SP-D, and the monoclonal antibody KL-6 were not elevated. However, the levels of carcinoembryonic antigen and carbohydrate antigen $19-9$ were $193.1 \mathrm{ng} / \mathrm{mL}$ and $215 \mathrm{U} /$ $\mathrm{mL}$, respectively, which was slightly elevated. CT showed infiltrative shadows with cavities in the left S1+2 through S4 lung field (Fig. 3). Although inflammatory changes were considered, because the blood test results for inflammatory markers were unremarkable and infection was ruled out, we speculated that a rupture of pulmonary metastatic lesions oc- 

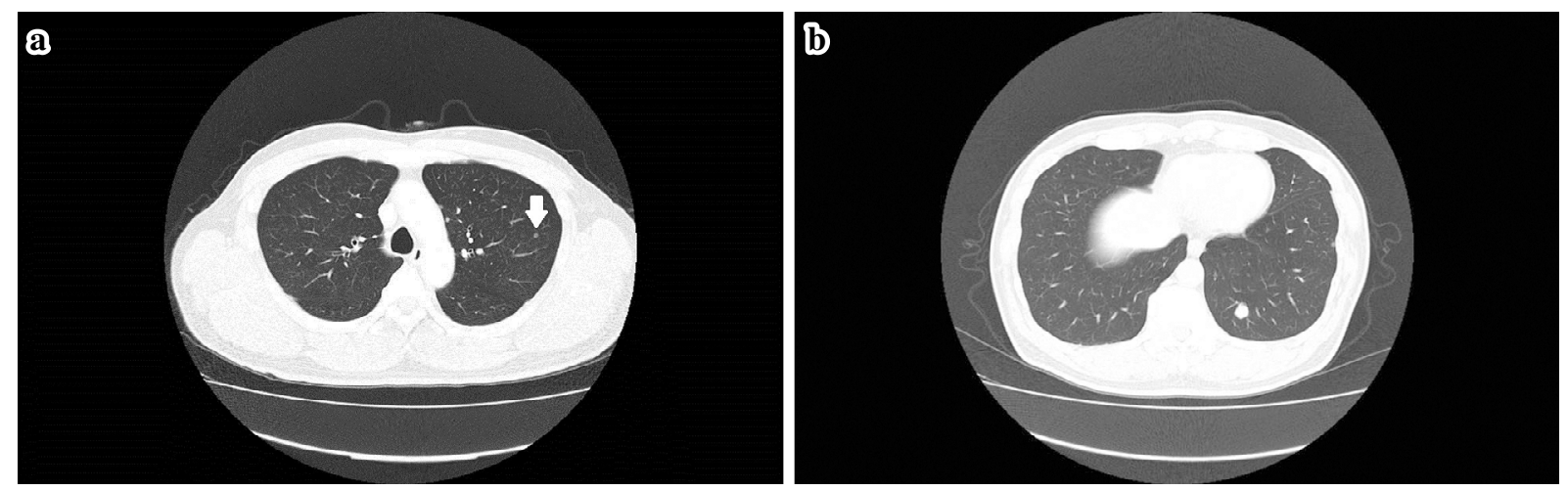

Figure 1. a, b: Computed tomography findings suggested multiple lung metastases in both lung fields (arrow).
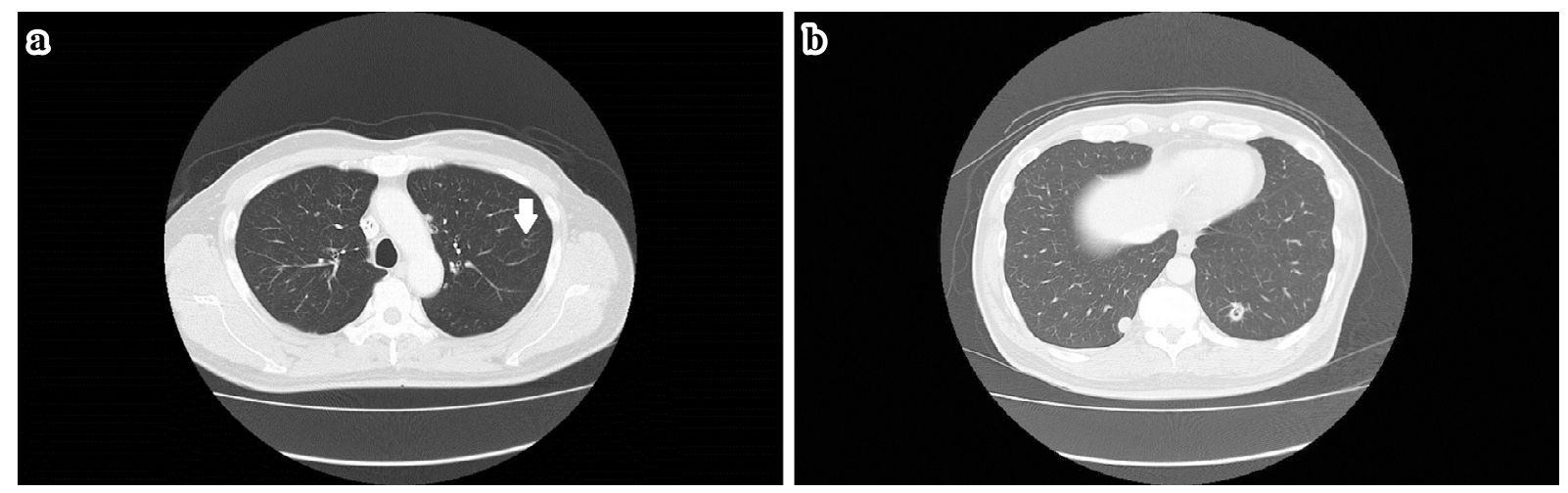

Figure 2. a, b: After bevacizumab+XELOX (capecitabine, oxaliplatin) therapy was started, cavitation within the pulmonary metastatic lesions was observed; the cavitation was considered to be caused by bevacizumab (arrow).

curred, leading to bleeding. Two days after hospitalization on the same day of the follow-up, the patient experienced difficulty breathing, and chest radiography as well as CT showed a pneumothorax. In addition, the infiltrative shadows that were observed from the $\mathrm{S} 1+2$ through $\mathrm{S} 4$ field appeared as massive bullae, around which dense infiltrative shadows that extended up to the pleura were observed (Fig. 4). The rapid alteration in the left lung was presumably caused by both a rupture and bleeding that occurred from a part of the pulmonary metastatic lesions. Furthermore, the airspace expanded in the form of a check valve to generate the bullae, which infiltrated into the pleura and led to the formation of the pneumothorax. Despite chest drainage and continuous aspiration, an air leak persisted over 4 weeks. Pleurodesis with autologous blood was conducted twice, however, the patient's condition did not improve. Therefore, surgical treatment was scheduled.

\section{Discussion}

BV specifically binds to vascular endothelial growth factor (VEGF)-A and inhibits its binding to VEGF receptor (VEGFR)-1 and VEGFR-2, thereby inhibiting VEGF signal transduction. BV exerts antitumor effects by causing ischemic alterations, such as microvascular involution in tumors and suppression of tumor angiogenesis, and improves the delivery of chemotherapeutic drugs through normalization of the vascular plexus in tumors (1-3). BV has been widely used for the treatment of lung cancer and breast cancer in addition to colon cancer. However, hypertension, proteinuria, and delayed wound healing are common side effects of BV therapy. In other cases, bleeding and severe side effects such as gastrointestinal bleeding have been reported (4-6).

As mechanisms underlying BV-induced bleeding, vascular endothelial damage due to inhibition of angiogenesis and abnormal coagulation due to VEGF depletion in platelets, which causes the formation of thrombi, have been reported (7). Epistaxis and alveolar hemorrhage have been reported to be caused by BV $(8,9)$. Bleeding is light in most patients, and severe bleeding occurs in $1.37 \%$ of the patients. However, a meta-analysis that included lung cancer cases showed that bleeding is the most common cause of death related to BV treatment (10). Thus, bleeding from lung lesions should be especially considered, as in the case of our patient. 

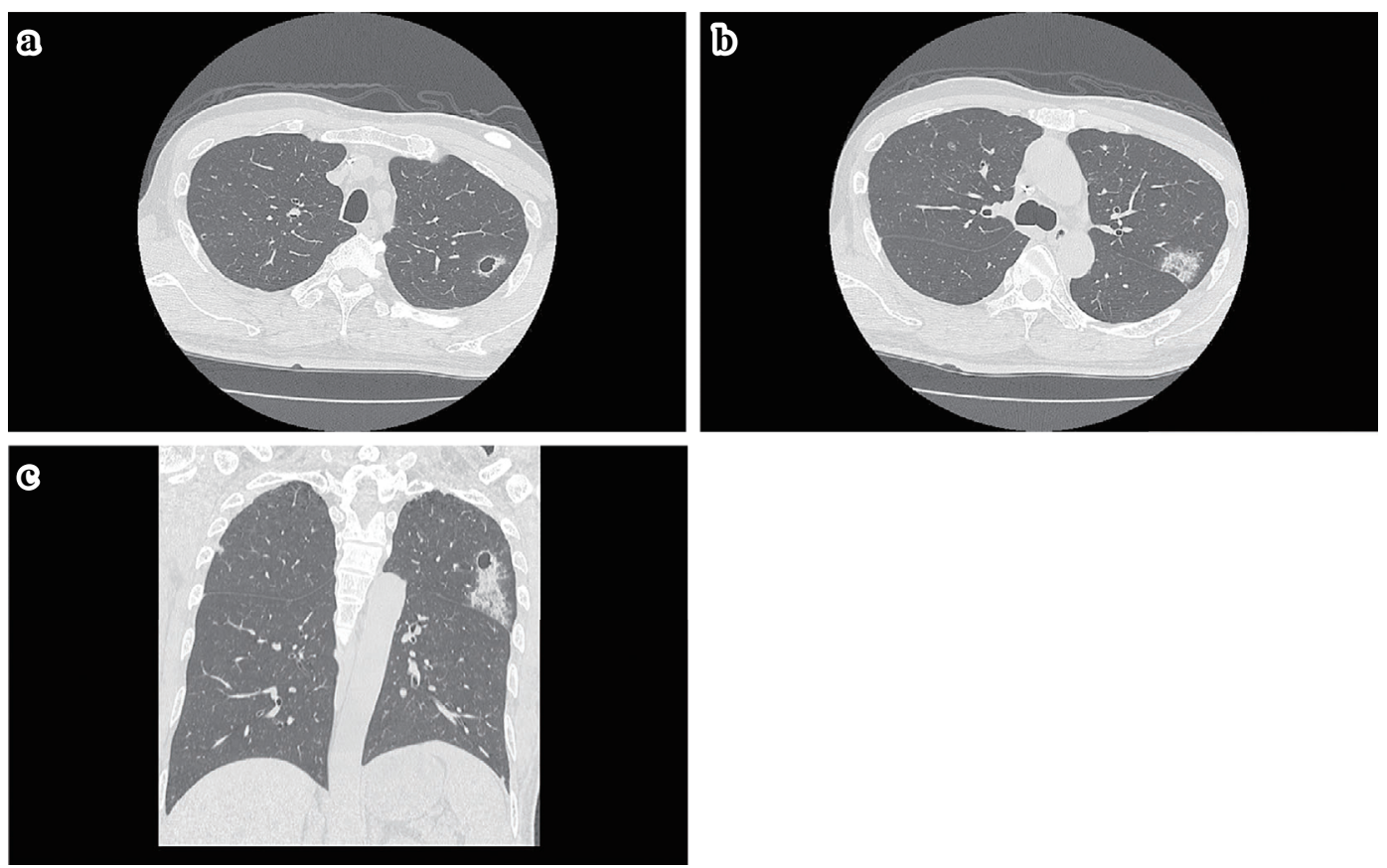

Figure 3. a-c: After 8 courses of bevacizumab+XELOX (capecitabine, oxaliplatin) therapy, lung metastases showed a transition to progressive disease. Thereafter, bevacizumab+FOLFIRI (irinotecan, l-leucovorin, 5-fluorouracil) therapy was started. On day 4 of course 5, the patient experienced pain on the left side of his chest and was admitted to our hospital. CT showed infiltrative shadows with cavities in the left S1+2 through S4 lung field. Although inflammatory changes were considered, because the blood test results for inflammatory markers were unremarkable and infection was ruled out, we speculated that a rupture of pulmonary metastatic lesions occurred, leading to bleeding.
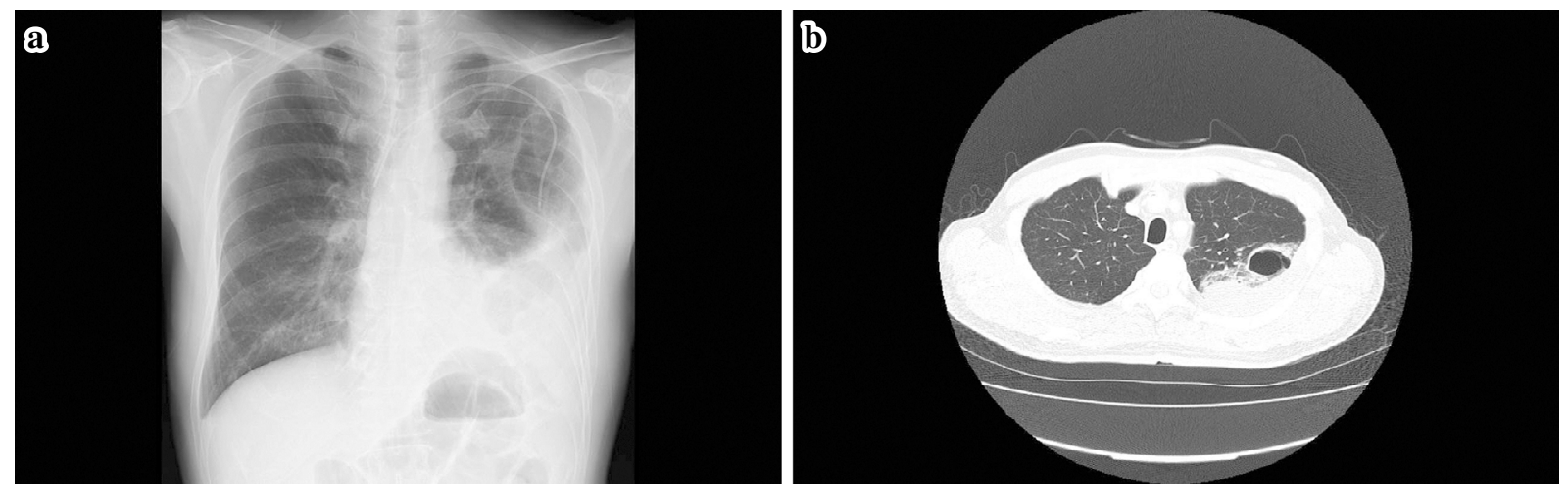

Figure 4. a, b: Two days after hospitalization, chest radiography as well as CT showed pneumothorax. In addition, the infiltrative shadows that were observed from the $\mathrm{S} 1+2$ through $\mathrm{S} 4$ field appeared as massive bullae, around which dense infiltrative shadows that extended up to the pleura were observed. The rapid alteration in the left lung was presumably caused by rupture and bleeding that occurred from a part of the pulmonary metastatic lesions. Furthermore, the airspace expanded in the form of a check valve to generate the bullae, which infiltrated into the pleura and led to the formation of the pneumothorax.

A side effect of BV treatment, pneumothorax, is not widely recognized, however, several cases have been reported (11-14). Various causes of pneumothorax during chemotherapy have been surmised. Yamada et al. classified them as follows: [1] bullae or blebs directly under the pleura accidentally rupture during chemotherapy; [2] bronchopleu- ral fistulas are formed because of tumor necrosis; [3] pleural lesions are secondarily caused by damage to the lung parenchyma induced by chemotherapy or radiation therapy; [4] cavities or emphysematous lesions are formed in the peripheral tissues and rupture by the check-valve mechanism because of obstruction or stenosis of bronchi due to tumors; 
Table. Cases of Pneumothorax after Bevacizumab-containing Chemotherapy.

\begin{tabular}{|c|c|c|c|c|c|c|c|c|c|}
\hline References & $\begin{array}{l}\text { Age } \\
\text { Sex }\end{array}$ & $\begin{array}{l}\text { BMI } \\
\left(\mathrm{kg} / \mathrm{m}^{2}\right)\end{array}$ & Diagnosis & CTx & Onset & Imaging & Treatment & Outcome & $\begin{array}{l}\text { Subsequent } \\
\text { use of BV }\end{array}$ \\
\hline 11) & $\begin{array}{l}45 \\
M\end{array}$ & N.D. & $\begin{array}{l}\text { Colon cancer } \\
\text { Lung meta. }\end{array}$ & $\begin{array}{l}\text { BV } \\
\text { FOLFOXIRI }\end{array}$ & $\begin{array}{l}\text { 21days } \\
\text { (2nd cycle) }\end{array}$ & $\begin{array}{l}\text { Xp: Right-side } \\
\text { pneumothorax }\end{array}$ & $\begin{array}{l}\text { Chest tube } \\
\text { insertion }\end{array}$ & $\begin{array}{l}\text { Recovery } \\
\text { in } 5 \text { days }\end{array}$ & N.D. \\
\hline 12) & $\begin{array}{l}70 \\
F\end{array}$ & 22.0 & $\begin{array}{l}\text { Pulmonary } \\
\text { cancer }\end{array}$ & $\begin{array}{l}\text { BV } \\
\text { CBDCA, PTX }\end{array}$ & $\begin{array}{l}\text { 7days } \\
\text { (1st cycle) }\end{array}$ & $\begin{array}{l}\text { Xp, CT: Left-side } \\
\text { pneumothorax } \\
\text { CT: Hollowing } \\
\text { tumor inside }\end{array}$ & $\begin{array}{l}\text { Chest tube } \\
\text { insertion } \\
\text { Pleurodesis }\end{array}$ & $\begin{array}{l}\text { Recovery } \\
\text { in } 45 \text { days }\end{array}$ & - \\
\hline 13) & $\begin{array}{l}23 \\
\mathrm{M}\end{array}$ & N.D. & Fibrosarcoma & $\begin{array}{l}\text { BV } \\
\text { DTX, CDDP }\end{array}$ & $\begin{array}{l}55 \text { days } \\
\text { (3rd cycle) }\end{array}$ & $\begin{array}{l}\text { Xp: Bilateral } \\
\text { pneumothorax }\end{array}$ & $\begin{array}{l}\text { Chest tube } \\
\text { insertion }\end{array}$ & $\begin{array}{l}\text { Recovery } \\
\text { in 3days }\end{array}$ & + \\
\hline 14) & $\begin{array}{l}62 \\
F\end{array}$ & N.D. & $\begin{array}{l}\text { Breast cancer } \\
\text { Lung meta. }\end{array}$ & $\begin{array}{l}\text { BV } \\
\text { PTX }\end{array}$ & 8 months & $\begin{array}{l}\text { Xp, CT: Left-side } \\
\text { pneumothorax } \\
\text { CT: Hollowing } \\
\text { tumor inside }\end{array}$ & $\begin{array}{l}\text { Chest tube } \\
\text { insertion } \\
\text { Pleurodesis }\end{array}$ & $\begin{array}{l}\text { Recovery } \\
\text { in 6weeks }\end{array}$ & - \\
\hline Our case & $\begin{array}{l}57 \\
\mathrm{M}\end{array}$ & 22.1 & $\begin{array}{l}\text { Colon cancer } \\
\text { Lung meta. }\end{array}$ & $\begin{array}{l}\text { BV } \\
\text { FOLFIRI }\end{array}$ & $\begin{array}{l}\text { 6months } \\
\text { (13th cycle) }\end{array}$ & $\begin{array}{l}\text { Xp, CT: Left-side } \\
\text { pneumothorax } \\
\text { CT: Consolidation } \\
\rightarrow \text { Bulla }\end{array}$ & $\begin{array}{l}\text { Chest tube } \\
\text { insertion } \\
\text { Pleurodesis }\end{array}$ & $\begin{array}{l}\text { No recovery } \\
\text { in } 3 \text { weeks }\end{array}$ & - \\
\hline
\end{tabular}

BMI: Body Mass Index, CTx: Chemotherapy, BV: Bevacizumab, N.D.: Not Detected, meta.: metastasis, FOLFOXIRI: 5-Fluorouracil, Oxaliplatin,

Irinotecan, CBDCA: Carboplatin, DTX: Docetaxel, CDDP: Cisplatin, PTX: Paclitaxel, FOLFIRI: 5-Fluorouracil, L-Leucovorin, Irinotecan

and [5] the intrathoracic pressure is elevated due to vomiting as a side effect of chemotherapy, resulting in rupture of the pleura (15). Routine treatment with BV frequently leads to tumor necrosis. In lung metastases of sarcoma, tumor necrosis occurs in response to chemotherapy and leads to internal cavitation, which results in secondary spontaneous pneumothorax in most patients $(11,16)$. In the current case, small solid pulmonary metastatic lesions that were rather close to the pleura presumably transitioned into the hollow spaces because of tumor necrosis caused by BV. Thereafter, bleeding ensued at the same sites, presumably because BV caused expansion of the airspace in the form of a check valve to generate the bullae, which infiltrated into the pleura to form the pneumothorax. Thus, bleeding might have triggered the development of the pneumothorax.

In the present case, because a pneumothorax occurred in the middle of BV + FOLFIRI therapy as second-line chemotherapy, the possibility that 5-FU or CPT-11 was responsible for the pneumothorax could not be ruled out. However, there are no previous reports of 5-FU or CPT-11-induced pneumothorax; therefore, it is likely that bevacizumab caused a rupture of the lung metastatic lesion of colon cancer, leading to the pneumothorax.

In our review of reports on the occurrence of pneumothorax caused by BV (11-14; Table), a total of 4 cases of lung lesions were identified. Of them, 3 cases were of lung me- tastasis and 1 was of primary lung cancer. In 1 case of fibrosarcoma, a lung lesion was not observed. Thus, a pneumothorax can occur in cases where a lung lesion is not observed, although a pneumothorax is frequently caused by treatment for lung lesions. Agents used in combination with BV were 5-FU $(n=2)$, platinum $(n=3)$, taxanes $(n=3)$, and CPT-11 ( $\mathrm{n}=2)$, and in some cases, more than 1 agent was used in combination with $\mathrm{BV}$, none of which was characteristic. The time to occurrence of pneumothorax widely varied: 7 days through 8 months after BV therapy or at the first or 13th administration of BV. Therefore, a pneumothorax may occur not only in the early stage of BV administration, but also after several months, as observed in the case of our patient. In most cases, internal tumor necrosis was observed on imaging; necrosis is thought to result in the formation of bronchopleural fistulas and represents the mechanism underlying the development of pneumothorax (15), as stated above. However, in the case of our patient, the bullae were thought to have formed because of bleeding, a major side effect of $\mathrm{BV}$, and consequently led to the development of the pneumothorax. Our findings differ from those of previous studies. For the treatment of pneumothorax, chest drainage was conducted in all the patients; in cases where the improvement was unsatisfactory, pleurodesis was conducted, similar to our case. In some patients, an improvement was observed within several days after pleurodesis, whereas in 
some other patients, this treatment had to be continued for several weeks, as in the case of our patient. Because the half-life of BV is 20 days and we frequently administered $\mathrm{BV}$, similar to the treatment protocol used by Makino et al. (14), ischemic alteration, an antitumor effect of BV, possibly accumulated and delayed the wound-healing process, a side effect of $\mathrm{BV}$, thereby affecting the outcome. In the case of our patient, this condition did not improve at week 3 of the treatment; therefore, surgical treatment, a radical operation for pneumothorax, was scheduled. After alleviation of a pneumothorax, resumption of chemotherapy is certainly considered. Only Zhang et al. (13) reported that they readministered BV a week after alleviation of a pneumothorax on the right side of their patient's chest. Thus, BV readministration is not necessary. In particular, for patients without KRAS mutations, such as the patient in our case, anti-epidermal growth factor receptor (EGFR) agents, including cetuximab and panitumumab, can be used without the need for BV readministration. Therefore, we plan to conduct combination chemotherapy with anti-EGFR agents after alleviation of the pneumothorax for the present case.

We herein experienced the case of a patient who showed bleeding from pulmonary metastatic lesions after BV administration and developed an intractable pneumothorax. To the best of our knowledge, this is the first case wherein a pneumothorax was caused by bleeding from pulmonary metastatic lesions, which is an important mechanism underlying $\mathrm{BV}$-induced pneumothorax.

The authors state that they have no Conflict of Interest (COI).

\section{References}

1. Ferrara N. Vascular endothelial growth factor: basic science and clinical progress. Endocr Rev 25: 581-611, 2004.

2. Hicklin DJ, Ellis LM. Role of the vascular endothelial growth factor pathway in tumor growth and angiogenesis. J Ciln Oncol 23: 1011-1027, 2005.

3. Jain RK. Normalization of tumor vasculature: an emerging concept in antiangiogenic therapy. Science 307: 58-62, 2005.

4. Van CE, Rivera F, Berry S, et al. Safety and efficacy of first-line bevacizumab with FOLFOX, XELOX, FOLFIRI and fluoropyrimidines in metastatic colorectal cancer: the BEAT study. Ann Oncol 20: 1842-1847, 2009.

5. Shord SS, Bressler LR, Tierney LA, Cuellar S, George A. Understanding and managing the possible adverse effects associated with bevacizumab. Am J Health Syst Pharm 66: 999-1013, 2009.

6. Hapani S, Chu D, Wu S. Risk of gastrointestinal perforation in patients with cancer treated eith bevacizumab: a meta-analysis. Lancet Oncol 10: 559-568, 2009.

7. Verheul HM, Lolkema MP, Qian DZ, et al. Platelets take up the monoclonal antibody bevacizumab. Clin Cancer Res 13: 53415347, 2007.

8. Yanagihara $\mathrm{K}$, Takei $\mathrm{H}$, Iida $\mathrm{S}$, et al. Grade 4 epistaxis in a woman with metastatic breast cancer treated with bevacizumab: a case report. J Nippon Med Sch 81: 333-336, 2014.

9. Ikeda S, Sekine A, Kato T, et al. Diffuse alveolar hemorrhage as a fatal adverse effect of bevacizumab: an autopsy case. Jpn J Clin Oncol 44: 497-500, 2014.

10. Ranpura V, Hapani S, Wu S. Treatment-related mortality with bevacizumab in cancer patients: a meta-analysis. JAMA 305: 487494, 2011.

11. Yang SH, Lin JK, Chen WS, et al. Pneumothorax after bevacizumab-containing chemotherapy: a case report. Jpn J Clin Oncol 41: 269-271, 2011.

12. Tamura T, Tamura S, Nasu H, Fujimoto T, Kinoshita T. A case of intractable pneumothorax in a patient with pulmonary adenocarcinoma during bevacizumab-containing chemotherapy. Nihon Kokyuki Gakkai Zasshi 49: 702-706, 2011 (in Japanese, Abstract in English).

13. Zhang Y, Yang H, Zhao M, He J. Bilateral pneumothorax after bevacizumab-containing chemotherapy in fibrosarcoma. $\mathrm{J}$ Thorac Dis 4: 229-231, 2012.

14. Makino T, Kudo S, Ogata T. Pneumothorax after treatment with bevacizumab-containing chemotherapy for breast cancer - a case report. Gan To Kagaku Ryoho 41: 233-235, 2014 (in Japanese, Abstract in English).

15. Yamada N, Abe N, Usui K, et al. Clinical analysis of 12 cases of pneumothorax during intensive chemotherapy for malignant neoplasms. Gan To Kagaku Ryoho 37: 1519-1523, 2010 (in Japanese, Abstract in English).

16. Fayda M, Kebudi R, Dizdar Y, et al. Spontaneous pneumothorax in children with osteosarcoma: report of three cases and review of the literature. Acta Chir Belg 112: 378-381, 2012.

The Internal Medicine is an Open Access article distributed under the Creative Commons Attribution-NonCommercial-NoDerivatives 4.0 International License. To view the details of this license, please visit (https://creativecommons.org/licenses/ by-nc-nd/4.0/).

(C) 2016 The Japanese Society of Internal Medicine http://www.naika.or.jp/imonline/index.html 